\title{
Controversies in the Management of Open Fractures
}

\author{
C.L. O’Brien, M. Menon and N.M. Jomha*
}

Division of Orthopaedic Surgery, Department of Surgery, University of Alberta, Edmonton, Canada

\begin{abstract}
Open fractures are a common problem encountered by orthopaedic surgeons and comprise a broad spectrum of trauma. Management is guided by principle-based steps aimed at reducing the risk of gas gangrene or suppurative infections, whilst maintaining viability in a favourable soft tissue environment to reduce the risk of delayed or non-union of bone. Aspects of these principles, however, create discussion around several areas of controversy. The specific antimicrobial regimen and its duration are questions that have been evaluated for decades. Like the ever-evolving nature of the bacterial pathogens, the answer to this is dynamic and changing. The "six-hour rule" is a hotly debated topic with fervent perseverance of this dogma despite a gross lack of support from the literature. The most appropriate soft tissue management approach for open fractures - immediate definitive soft tissue closure versus leaving wounds open for delayed closure or definitive management - is also an area of debate. Exploration of these controversies and consideration for the historical context of the supporting literature furthers our understanding of the critical elements.
\end{abstract}

Keywords: Antibacterial agents, antibiotics, compound fracture, debridement, open fracture, surgery.

\section{INTRODUCTION}

Open fractures represent a spectrum of injuries sharing the common feature of fractures that have communication with the environment. These range from small inside-out puncture wounds to more extensive injuries representative of high-energy trauma; acknowledgement of the significant damage to surrounding tissues (skin, subcutaneous layer, muscle, tendons, and neurovascular structures) is imperative. Open fracture management comprises a series of principlebased steps to guide initial emergency management, then primary and definitive orthopaedic management, and finally rehabilitation. Awareness and implementation of Advanced Trauma Life Support [1] and tetanus management principles are critical to integrate into the approach, but will not be covered here. Ultimately, the goal is to prevent development of infection, obtain union of the fracture, and restore function of the limb.

Greater tissue destruction in higher energy cases leads to increased risk of developing complications of wound infection or non-union $[2,3]$. This relates to the critical contribution of local vascularity in host defense again micro-organisms [4]. In general, open fractures are classified into three types [5] whereby, the lower energy injuries are represented by the lowest grade with increasing grades for higher energy injuries. Commensurate with the increasing tissue injury involved, complication risk increases with grade. For example, Type I fractures are at $0-2 \%$ risk of developing infection, Type II have a $2-12 \%$ risk, while Type III have a $10-50 \%$ risk $[4,6,7]$. Infection risk is also related to increasing numbers of immunecompromising factors in the patient [8].

*Address correspondence to this author at the Division of Orthopaedic Surgery, Department of Surgery, University of Alberta, Edmonton, Canada; Tel: 1780407 2816; Fax: 1780407 2819; E-mail: njomha@ualberta.ca
The clinical expertise guiding the principles of open fracture management is based on a combination of historical experiences and tradition, basic science, and clinical research evidence. Advances in trauma musculoskeletal care has led to an evolution over time in what is accepted as the standard of care. Advances in antibiotics, implant and fixation methods, increasing incidence of nosocomial infections, and emphasis on efficient cost-effective care have generated a need to re-evaluate the standards of practice around open fractures $[9,10]$. Henry describes the role of "thorough early cleansing" in "frustrat(ing) the curse" of a septic outcome, citing examples of reduced rates of infection with meticulous surgical debridement dating back to the 1920s [11]. Trueta outlined a five point treatment program in 1942 for open fractures consisting of prompt surgery, wound cleansing, wound excision, provision of drainage, and fracture immobilization in a plaster cast, allowing soft tissue healing by secondary intention [12]. Speculation that the success and benefits of antibiotics perhaps contributed to some complacency in the surgical removal of necrotic tissues may have led to a resurgence of complication rates; systemic antibiotics are no substitute for adequate debridement [10].

Despite fluctuations in opinion and strategies, many open fracture treatment principles are widely accepted and supported; controversy and debate, however, still abound around several aspects of open fracture care. Appreciation for the historical context of the available research and altered microbiological and pharmacological landscape over time requires ongoing re-evaluation of the literature. Open fracture treatment principles are in constant evolution. Specifically, the issues of 1) appropriate antibiotic prophylaxis, 2) ideal timing for operative debridement, and 3 ) appropriate timing of wound closure after debridement will serve as the foci of interest in this review. 


\section{ANTIBIOTIC PROPHYLAXIS}

Prevention of infection remains one of the critical goals in open fracture treatment, though the methods utilized to achieve this goal have evolved over time. Infections can be grouped into invasive types such as in gas gangrene, or as the more common suppurative type [13]. Furthermore, they can be primary or secondary, the former implying the presence of a microbial pathogen from the time of initial injury, and the latter implying a subsequent contamination of the wound leading to wound sepsis. Prior to World War II antibiotics were not part of the armamentarium for treating open fractures. Invasive infections such as gas gangrene required devitalized and dead tissue to become established and these organisms thrived in an anaerobic environment; infection prevention necessitated "debridement and excision of all bruised tissue" [13-16]. Widespread availability of antibiotics, namely penicillin initially, occurred during World War II [17]. In the early papers, antibiotics were not yet widely available or acknowledged to be critical adjuncts in open fracture management. Advances in microbiology and pharmacology improved the understanding of the pathogens involved, leading to increased use of antibiotics.

High rates of positive bacterial culture from the initial wound can be obtained from open fractures [7, 18]. Prompt administration of antibiotics is a critical adjunct for decreasing infection after open fractures (in addition to surgical debridement of devitalized tissue and debris) and can be viewed more as treatment for presumptive infection or contamination, rather than simply prophylaxis [18]. Today, the need for, nor urgency of antibiotic administration does not spark a particularly controversial discussion in open fracture management, with compelling evidence demonstrating increased infection risk with delayed or no antibiotics [6, 19-22]. Patzakis' landmark study in 1974 and a subsequent meta-analysis definitively established systemic antibiotics as important adjuncts to reduce infection risk [19, 23]. Delay of antibiotic administration beyond three hours is related to an increased risk of infection [20].

The Gustilo and Anderson classification of open fractures $[5,7]$, though recognized to have poor intra-observer reliability $[24,25]$, helps prognostication and management planning. Most open fractures $(50-75 \%)$ are contaminated (i.e. will have a positive culture) prior to initial debridement $[5,19,26]$. Directing prophylaxis against the most relevant pathogens is a fundamental tenet, as no benefit of administration will be derived if pathogens are not susceptible to the chosen antimicrobial [17, 19]. Staphylococcus species and aerobic gram-negative bacteria are responsible for most infections $[6,19,27,28]$. The grampositive organisms predominate in the lower grade injuries, with an increased proportion of infections in high-grade fractures caused by gram-negative organisms $[7,26]$. Infections due to a larger proportion of bacteria resistant to the antibiotics prescribed have been noted after use of cephalosporins $[5,26]$. The particular distribution of pathogens appears to be evolving over time, with fluctuations in the proportion of gram-negative organisms or resistant bacteria in response to appropriate targeted antibiotics $[19,29]$. Of particular concern is that guidelines may promote use of antibiotics that cover a decreasing proportion of relevant pathogens [17]. Those organisms that are outside of the prescribed antibiotic's spectrum of activity seem to be those causing infection [26]. A high probability of developing a wound infection exists if resistant organisms comprise the initial contaminating flora of an open wound [19]. A meta-analysis of antimicrobials in open fractures revealed that the particular antibiotic regimens studied were likely to have been effective at the time of each respective study [23], but moving forward, selection of appropriate antimicrobial coverage for open fractures will need to evolve in response to the most pertinent pathogens of the time and region. With progressively higher MRSA colonization rates, re-evaluation of antibiotic guidelines is needed to ensure appropriate and effective targeting of infection-causing pathogens [17]. A threshold prevalence rate of MRSA does not yet exist to inform the switch of antimicrobial coverage [23].

Multiple reports evaluating various antimicrobial regimens have been published since the addition of antibiotics to the open fracture tool box [15, 27, 28]. Based on a systematic review of 49 studies, evidenced-based guidelines support early antibiotic coverage of gram positives in all grades of fracture, with addition of gram negative coverage in grade III fractures [30]. Monotherapy with a first generation cephalosporin (e.g. cefazolin) or fluroquinolone (e.g. ciprofloxacin) is common treatment of Grade I and Grade II injuries. Clindamycin has also been evaluated as potential monotherapy, but is not suitable on its own for Grade III injuries [31]. Gustilo's finding of an increased incidence of gram-negative organisms in their 1984 paper prompted a change in their antibiotic treatment recommendation: to combine an aminoglycoside with a first generation cephalosporin for Type III fractures [7]. Many guidelines continue to endorse this recommendation [32-34]. Robust evidence is lacking, however, for addition of gramnegative coverage in Grade III injuries [35, 36]. Use of antibiotics locally may also have a role. Combining a local antibiotic bead pouch with systemic prophylaxis reduced the infection rate significantly over parenteral systemic antibiotics alone [37]. The quality of evidence supporting local antibiotics, however, is low and warrants further study $[30,36,38]$.

The duration of antibiotic coverage also has varying opinions as to what is appropriate, with some studies indicating that the length of antibiotic administration isn't all that important [39]. Based on lack of demonstrated efficacy of prolonged (5-10 day) antibiotic regimens, 72 hours of antibiotic administration after open fractures is recommended by some, with repeated short courses for subsequent procedures [5, 38]. Even shorter $(<=24$ hour $)$ course of antibiotics have also not been shown to be inferior to longer courses in preventing infection after open fractures $[40,41]$. The British Orthopaedic Association/British Association of Plastic Reconstruction and Aesthetic Surgeons (BOA/BAPRAS) guidelines advocate 24-48 hours of antibiotics for Grade I fractures, and for Grade II and III fractures, a maximum 72 hours or until soft tissue coverage is achieved, whichever is the shorter duration [32].

Quoting Bergman, "no antibiotic can replace proper surgical management" [28], and although the microbial and pharmacological arms race will continue with growing bacterial resistance, bacteria are unlikely to develop 
resistance to surgical steel. A definitive statement of the "best" antibiotic regimen in open fractures will never be possible given the dynamic and evolving nature of the problem. It is therefore, critical that the Orthopaedic surgeon stay mindful of the historical context of each study when reviewing the literature and to be aware of the changing resistance patterns and available antimicrobials in their geographical area of practice so as to target prophylaxis appropriately. The length of antibiotic administration postsurgical debridement has not been satisfactorily investigated and varies anywhere up to 72 hours.

\section{TIMING TO THE OPERATING ROOM (OR)}

The controversy around timing of operative debridement for open fractures centers around the so-called "6-hour rule" that has persisted as adamant rhetoric in our consciousness. It is frequently touted in current practice guidelines, such as those posted by the BOA/BAPRAS [32] or EAST Practice Management Guidelines Work Group [38], as a standard to minimize infection complication risk. A recent systematic review concluded that strong support of "early surgical debridement" existed (within 24 hours) [30]. Basic science studies of wound colonization and bacterial adherence demonstrate a time-dependence of these factors that supports a need for urgency in debridement [42, 43]. The origin of this guideline is purported to come from Freidrich's guinea pig experiments from 1898 that found decreased effectiveness of debridement after six hours due to massive exponential bacterial replication [43-45].

Strict observance of a 6 hour cut off, however, has not borne out in the clinical evidence, with the severity of traumatic injury, anatomic location of injury (especially tibia), and patient comorbidities and smoking status being more predictive of infection risk [8, 20, 40, 44-46]. The literature varies in the description of what constitutes early debridement; some report time from injury, and others from time of presentation. Nevertheless, it does suggest that the sooner the patient receives antibiotic prophylaxis [20] and arrives at an appropriate treating trauma facility [47], the better it is for patient outcome. Delay in admission to the definitive treating trauma center of more than two hours after injury was associated with a 5.4 times increased risk of developing an infection [3]. A multitude of studies have evaluated the risk of infection and non-union with early and delayed debridement as will be discussed.

Two studies [48, 49] that found increased infection risk with delays have been widely criticized for small numbers and bias [2, 44, 50-53]. In general, a paucity of evidence exists to suggest that there is a benefit from an infection or non-union perspective when debridement occurs within 6 hours $[2,45,48,49,54]$. In fact, there is a multitude of evidence using higher quality studies and more patients that demonstrates a delay in surgical treatment within limits does not compromise patient outcome (Table 1). One major limitation in this bulk of literature indicating no increased adverse outcomes with delays to surgery is that these studies have typically involved comparisons of groups based on arbitrary cut-off times [45]. A recent study evaluating time as a continuous variable in a multivariate logistic regression model, however, identified a linear increase in the odds ratio for infection with time. Even though Hull reported a rise in infection risk per hour of delay, this seemed to apply mainly to high-grade, contaminated open tibial fractures (Grade IIIB and IIIC) with a much, if any, weaker relationship in other types of open fractures [45]. Overall, maintaining the status of open fractures as an orthopaedic emergency is important because many of the principles of care are time dependent. Extrapolating this to a guideline of urgency, rather than the traditionally applied dogmatic time cut-off (i.e. 6 hours) is perhaps more accurate and realistic. Mindful consideration of each unique clinical scenario, the availability of an appropriately experienced and prepared operative team, and the ease of availability of the operating room (e.g. protected trauma time) are important considerations while still seeking to expedite appropriate timely surgical debridement.

\section{PRIMARY CLOSURE AND EARLY COVERAGE VERSUS DELAYED CLOSURE/COVERAGE}

Addressing the plan for dealing with the soft tissue envelope is the next step after debridement. Many authors advocate a staged protocol for initial debridement followed by delayed wound closure to avoid the potential complications of a deep infection [5, 7, 19, 67]. Indeed, authors with experiences from both war and civilian practice have advocated leaving wounds open as the optimal management strategy $[12,14,43,68]$. Indeed, Gustilo advocated that it is imperative to re-debride crush or farm injury or associated vascular injury, as a high frequency of unappreciated tissue necrosis is present at 24 hours $[5,7]$. Others suggest that early coverage confers several advantages and benefits, without excessive risk [13, 29, 50, 64, 69-74]. Once again, definitions of timing vary when discussing closure, as do the relevant outcome measures of infection (deep and superficial), non-union/delayed union, and osteomyelitis [10]. Immediate closure typically refers to timing less than 72 hours, but delayed closure ranges in the literature from greater than 72 hours to more than three months post-injury $[37,43,73,74]$. Which approach is most appropriate is indeed a controversial topic and selecting a management strategy can often be an exercise in calculated risks. Again, in evaluating the studies for and against early closure, it is important to consider them within their historical context.

The benefits of a staged approach include ensuring that late declaration of non-viable tissue is identified and avoiding generation of an anaerobic environment, which might risk the development of clostridial myonecrosis (gas gangrene) [6]. In the pre-antibiotic era, allowing for continued drainage from the open wound was an important strategy [14]. Closure of high-grade tibial fractures in one study resulted in unacceptably high rates of infection $(44 \%$ compared to $20 \%$ with delayed closure strategy) [5]. Aggressive debridement protocols that remove all tissue of questionable viability may create problems due to segmental bone loss, delayed union, and commit the patient to further surgical interventions [75]. A retrospective review of 29 open supracondylar femur fractures compared more and less aggressive debridement protocols, and found that retaining marginal viability fragments whilst still removing grossly contaminated or completely devitalized bone fragments was favoured to balance the outcomes of osseous healing and infection risk [75]. Serial debridement every 48 hours, with 
Table 1. Studies showing no detrimental consequences to operative debridement greater than 6 hours.

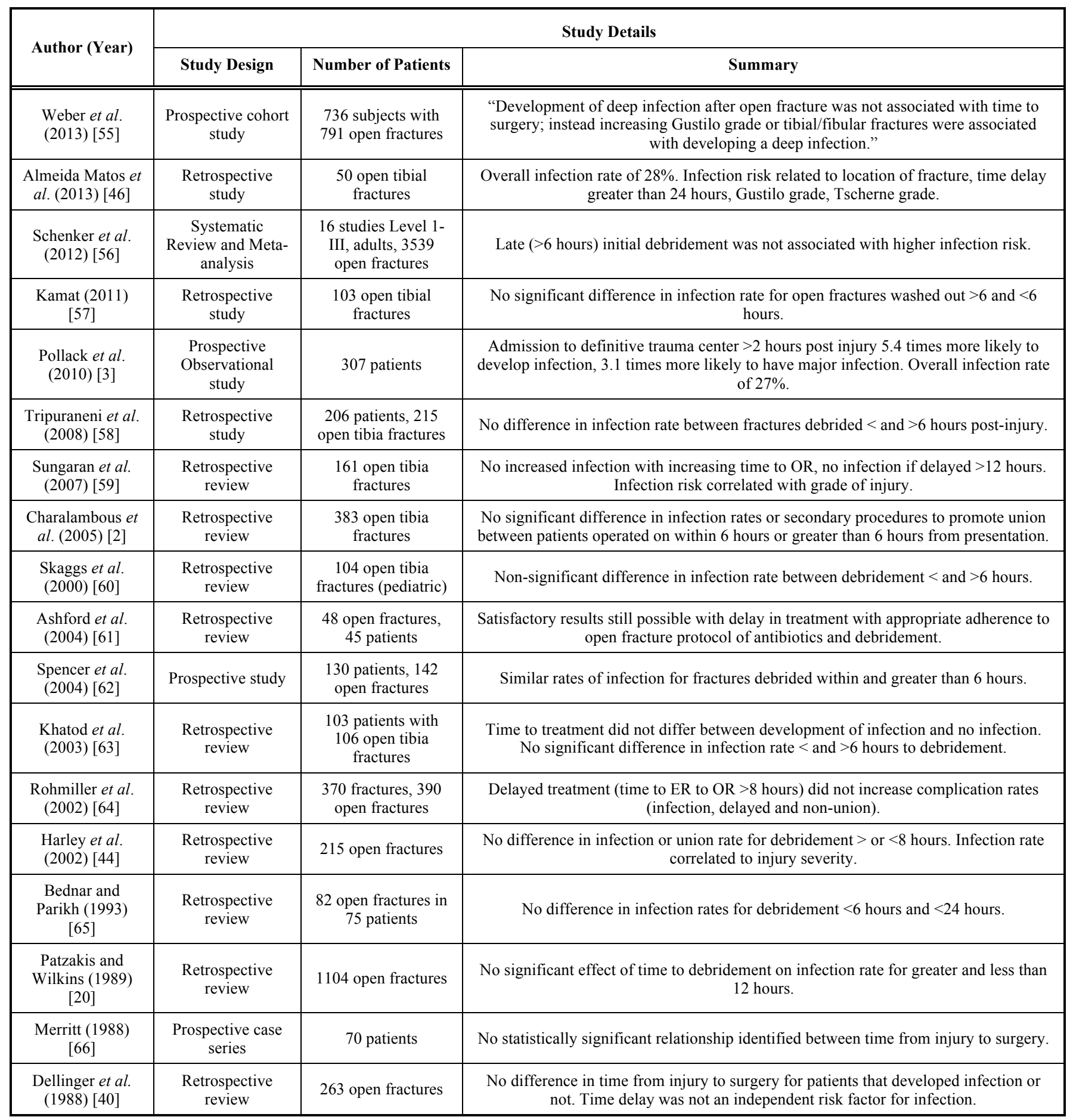

delay of closure until achievement of negative postdebridement cultures, can produce low rates of deep infections (5.7\% in Grade III injuries; $1.3 \%$ in IIIA, $10.6 \%$ in IIIB, $20 \%$ in IIIC) and avoid the problems of excessive debridement [76]. The downsides, however, are that multiple surgical procedures are required, it delays healing and discharge, and the risk of nosocomial infection is increased [7], and may be associated with more wound problems [70].

Protocols predicated on early appropriate antibiotic administration, aggressive initial debridement, and primary wound closure might avoid the wound problems and nosocomial infection risk without leading to the historical potential complications of gas gangrene [29, 64, 69-74]. Several studies have demonstrated that with meticulous attention to ensuring an extensive and aggressive initial debridement, primary closure of even high grade tibial wounds can be achieved without increased risk of infection or non-union development [64, 69-73]. Surgical judgment is required for successful use of an immediate wound closure protocol $[10,13]$. Surgical judgment in open fractures, however, can be challenging even for the most experienced surgeons [13]. Thus, finding the balance on the spectrum of 
potential risks and complications is the fundamental principle guiding decision making for debridement and coverage strategies.

Inappropriate closure of severely contaminated wounds, wounds that have not been adequately debrided of foreign or necrotic tissues, and absent or inadequate adjunctive antibiotic use cannot be used as justification for the need for delayed closure [10]. Contraindications for immediate closure of wounds include gross contamination with feces, dirt, stagnant water, farm injuries, fresh water injuries, delay to initiation of antibiotics $>12$ hours, and questionable tissue viability at initial surgery. It would appear, however, that satisfactory clinical results and outcomes can be obtained with the consistent application of either immediate or delayed closure protocols, understanding that each approach has particular trade-offs.

\section{SUMMARY}

Open fracture management requires respect for several universally accepted principles in order to mitigate the risks of infection and non-union. Advances in surgical, microbial, and pharmacological understanding have contributed to changes over time in these principles, but changes in pathogen types and resistance patterns must also be recognized as an important driver precluding definitive statements regarding appropriate antimicrobial treatment. Surgical debridement of open fractures should be performed urgently, but the risk of infection and non-union is not strongly correlated to a delay to surgery. Appropriate consideration of fracture, patient, surgeon, and resource factors is likely of more utility. Both immediate closure and delayed closure of open wounds can be performed safely, though each has trade-offs. Several further controversies in open fracture management that were not discussed include a) non-operative management of pediatric grade I open fractures, b) irrigation solutions and volumes, c) early versus delayed fracture stabilization, and d) augmentation of fracture healing.

\section{CONCLUSION}

1. Open fractures are complex and challenging injuries that require principle based care to achieve optimal results.

2. Early administration of antibiotics is important, with coverage targeted at the anticipated pathogenic organisms based on the grade of injury. Growing prevalence of resistant organisms necessitates reconsideration of general and local practices. Prolonged duration of antimicrobial administration is not supported.

3. While open fractures should still be considered a surgical emergency, definite time thresholds for the timing prior to surgical debridement that increases risk of complications have not been determined. It is important to proceed with a timely adequate debridement informed by injury characteristics and resource availability, focusing on patient safety.

4. Aggressive early debridement can allow for primary closure of some open wounds without adverse consequences, and may confer a number of benefits. Ignorance of contraindications for closure could be anticipated to lead to complications.

5. Open fractures should be managed urgently, taking into consideration patient factors, surgeon factors, and resource factors.

\section{CONFLICT OF INTEREST}

No benefits in any form have been or will be received from a commercial party related directly or indirectly to the subjects of this manuscript.

\section{ACKNOWLEDGEMENTS}

Thanks to the University of Alberta Health Scott Library for the assistance in acquiring the reviewed studies.

\section{REFERENCES}

[1] Advanced Trauma Life Support Student Course Manual. $8^{\text {th }}$ ed. American College of Surgeons, Chicago 2008.

[2] Charalambous CP, Siddique I, Zenios M, et al. Early versus delayed surgical treatment of open tibial fractures: effect on the rates of infection and need of secondary surgical procedures to promote bone union. Injury 2005; 36(5): 656-61.

[3] Pollak AN, Jones AL, Castillo RC, Bosse MJ, MacKenzie EJ LEAP Study Group. The relationship between time to surgical debridement and incidence of infection after open high-energy lower extremity trauma. J Bone Joint Surg 2010; 92(1): 7-15.

[4] Neubauer T, Bayer GS, Wagner M. Open fractures and infection. Acta Chir Orthop Traumatol Cech 2006; 73(5): 301-12.

[5] Gustilo RB, Anderson JT. Prevention of infection in the treatment of one thousand and twenty-five open fractures of long bones: retrospective and prospective analyses. J Bone Joint Surg Am 1976; 58(4): 453-8.

[6] Zalavras CG, Marcus RE, Levin LS, Patzakis MJ. Management of open fractures and subsequent complications. Instr Course Lect 2008; 57: 51-63.

[7] Gustilo RB, Mendoza RM, Williams DN. Problems in the management of type III (severe) open fractures: a new classification of type III open fractures. J Trauma 1984; 24(8); 742 6.

[8] Bowen TR, Widmaier JC. Host classification predicts infection after open fracture. Clin Orthop Relat Res 2005; (433): 205-11.

[9] Barie PS. Breaking with tradition: evidence-based antibiotic prophylaxis of open fractures. Surg Infect 2006; 7(4): 327-9.

[10] Weitz-Marshall AD, Bosse MJ. Timing of closure of open fractures. J Am Acad Orthop Sur 2002; 10(6): 379-84.

[11] Henry AK. Extensile Exposure, $2^{\text {nd }}$ ed. E \& S Livingstone Ltd. 1957; p. 12.

[12] Trueta J. Treatment of war wounds and fractures. Br Med J 1942; 1(4245): 616-7.

[13] Hampton OP. Basic principles in management of open fractures. J Am Med Assoc 1955; 159(5): 417-9.

[14] Trueta J. "Closed" treatment of war fractures. Lancet 1939; 233(6043): 1452-5.

[15] Hampton OP. Preoperative and postoperative management of open fractures. Clin Orthop Relat Res 1965; 38: 14-8.

[16] Hampton OP. Management of open fractures and open wounds of joints. J Trauma 1968; 8(3): 475-8.

[17] Saveli CC, Belknap RW, Morgan SJ, Price CS. The role of prophylactic antibiotics in open fractures in an era of communityacquired methicillin-resistant Staphylococcus aureus. Orthopedics 2011; 34(8): 611-6; quiz 617.

[18] Lawrence RM, Hoeprich PD, Huston AC, Benson DR, Riggins RS. Quantitative microbiology of traumatic orthopedic wounds. J Clin Microbiol 1978; 8(6): 673-5.

[19] Patzakis MJ, Harvey JP, Ivler D. The role of antibiotics in the management of open fractures. J Bone Joint Surg Am 1974; 56(3): 532-41. 
[20] Patzakis MJ, Wilkins J. Factors influencing infection rate in open fracture wounds. Clin Orthop Relat Res 1989; (243): 36-40.

[21] Wilkins J, Patzakis M. Choice and duration of antibiotics in open fractures. Orthop Clin North Am 1991; 22(3): 433-7.

[22] Griffin M, Malahias M, Khan W, Hindocha S. Update on the management of open lower limb fractures. Open Orthop J 2012; 6: 571-7.

[23] Gosselin RA, Roberts I, Gillespie WJ. Antibiotics for preventing infection in open limb fractures. Cochrane Database Syst Rev 2004; (1): CD003764.

[24] Brumback RJ, Jones AL. Interobserver agreement in the classification of open fractures of the tibia. The results of a survey of two hundred and forty-five orthopaedic surgeons. J Bone Joint Surg Am 1994; 76(8): 1162-6.

[25] Horn BD, Rettig ME. Interobserver reliability in the Gustilo and Anderson classification of open fractures. J Orthop Trauma 1993; 7(4): 357-60.

[26] Carsenti-Etesse H, Doyon F, Desplaces N, et al. Epidemiology of bacterial infection during management of open leg fractures. Eur $\mathbf{J}$ Clin Microbiol Infect Dis 1999; 18(5): 315-23.

[27] Braun R, Enzler MA, Rittmann, WW. A double-blind clinical trial of prophylactic cloxacillin in open fractures. J Orthop Trauma 1987: 1(1): 12-7.

[28] Bergman BR. Antibiotic prophylaxis in open and closed fractures: a controlled clinical trial. Acta Orthop Scand 1982; 53(1): 57-62.

[29] Benson DR, Riggins RS, Lawrence RM, Hoeprich PD, Huston AC, Harrison JA. Treatment of open fractures: a prospective study. J Trauma 1983; 23(1): 25-30.

[30] Grote S, Polzer H, Prall, WC, et al. [Prevention of infection in the current treatment of open fractures: an evidence-based systematic analysis]Prävention von Infektionen bei offenen Frakturen heute: Ein evidenzbasierter systematischer review. Orthopäde 2012; 41(1): 32-42.

[31] Vasenius J, Tulikoura I, Vainionpää S, Rokkanen P. Clindamycin versus cloxacillin in the treatment of 240 open fractures: a randomized prospective study. Annales chirurgiae et gynaecologiae 1998; 87(3): 224-8.

[32] Nanchahal J, Nayagam S, Khan U, et al. xStandards for the management of open fractures of the lower limb. 1998 Retrieved from

http://www.bapras.org.uk/resources/clinical_guidance/open_fractur es_of_the_lower_limb [Accessed: February 18, 2014].

[33] Hoff WS, Bonadies JA, Cachecho R, Dorlac WC. East Practice Management Guidelines Work Group: update to practice management guidelines for prophylactic antibiotic use in open fractures. J Trauma 2011; 70(3): 751-4.

[34] Weber D. What is the best treatment for open fractures. In: Wright JG, Ed, Evidence-Based Orthopaedics: The best answers to clinical questions. Saunders Elsevier, United States 2009; pp. 313-6.

[35] Lane JC, Mabvuure NT, Hindocha S, Khan W. Current concepts of prophylactic antibiotics in trauma: a review. Open Orthop J 2012; 6: 511-7.

[36] Hauser CJ, Adams CA, Eachempati SR, Council of the Surgical Infection Society. Surgical Infection Society guideline: prophylactic antibiotic use in open fractures: an evidence-based guideline. Surg Infect 2006; 7(4): 379-405.

[37] Ostermann PA, Seligson D, Henry SL. Local antibiotic therapy for severe open fractures. A review of 1085 consecutive cases. J Bone Joint Surg Br 1995; 77(1): 93-7.

[38] Luchette FA, Bone LB, Born CT, et al. Practice Management Guidelines for Prophylactic antibiotic use in open fracture. EAST Practice Management Guidelines Work Group 2000; pp. 1-28.

[39] Wilkins J, Patzakis M. Choice and duration of antibiotics in open fractures The Orthop Clin North Am 1991; 22(3): 433-7.

[40] Dellinger EP, Caplan ES, Weaver LD, et al. Duration of preventive antibiotic administration for open extremity fractures. Arch Surg 1988; 123(3): 333-9

[41] Dunkel N, Pittet D, Tovmirzaeva L, et al. Short duration of antibiotic prophylaxis in open fractures does not enhance risk of subsequent infection. Bone Joint J 2013; 95-B(6): 831-7.

[42] Bhandari M, Schemitsch EH, Adili A, Lachowski RJ, Shaughnessy SG. High and low pressure pulsatile lavage of contaminated tibial fractures: an in vitro study of bacterial adherence and bone damage. J Orthop Trauma 1999; 13(8): 526-33.
[43] Crowley DJ, Kanakaris NK, Giannoudis PV. Debridement and wound closure of open fractures: the impact of the time factor on infection rates. Injury 2007; 38(8): 879-89.

[44] Harley BJ, Beaupre LA, Jones CA, Dulai SK, Weber DW. The effect of time to definitive treatment on the rate of non-union and infection in open fractures. J Orthop Trauma 2002; 16(7): 484-90.

[45] Hull PD, Johnson SC, Stephen DJ, Kreder HJ, Jenkinson RJ. Delayed debridement of severe open fractures is associated with a higher rate of deep infection. Bone Joint J 2014; 96-B(3): 379-84.

[46] Almeida Matos M, Castro-Filho RN, Pinto da Silva BV. Risk factors associated with infection in tibial open fractures. Revista de la Facultad de Ciencias Médicas 2013; 70(1): 14-8.

[47] Pollak AN, Castillo RC, Jones AL, et al. Time to definitive treatment significantly influences incidence of infection after open high-energy lower-extremity trauma. OTA Meeting Abstract, LEAP Study [Retrieved: February 4, 2014].

[48] Kindsfater K, Jonassen EA. Osteomyelitis in grade II and III open tibia fractures with late debridement. J Orthop Trauma 1995; 9(2): $121-7$.

[49] Kreder HJ, Armstrong P. A review of open tibia fractures in children. J Pediatr Orthop 1995; 15(4): 482-8.

[50] Okike K, Bhattacharyya T. Trends in the management of open fractures: a critical analysis. J Bone Joint Surg Am 2006 ; 88(12): 2739-48.

[51] Pollak AN. Timing of débridement of open fractures. J Am Acad Orthop Surg 2006; 14(10 Spec No.): S48-51.

[52] Jorge-Mora A, Rodriguez-Martin J, Pretell-Mazzini J. Timing issue in open fractures debridement: a review article. Eur J Orthop Surg Traumatol 2013; 23(2): 125-9.

[53] Werner CM, Pierpont Y, Pollak AN. The urgency of surgical débridement in the management of open fractures. J Am Acad Orthop Surg 2008; 16(7): 369-75.

[54] Jacob E, Erpelding JM, Murphy KP. A retrospective analysis of open fractures sustained by U.S. military personnel during Operation Just Cause. Mil Med 1992; 157(10): 552-6.

[55] Weber D, Dulai S, Bergman J, Buckley R, Beaupre L. Time to definitive operative treatment following open fracture does not impact development of deep infection: a prospective cohort study of 736 subjects. OTA Abstracts 2013: pp. 1-16.

[56] Schenker ML, Yannascoli S, Baldwin KD, Ahn J, Mehta S. Does timing to operative debridement affect infectious complications in open long-bone fractures? A systematic review. J Bone Joint Surg 2012; 94(12): 1057-64.

[57] Kamat AS. Infection rates in open fractures of the tibia: is the 6hour rule fact or fiction. Adv Orthop 2011; 2011: 943495.

[58] Tripuraneni K, Ganga S, Quinn R, Gehlert R. The effect of time delay to surgical debridement of open tibia shaft fractures on infection rate. Orthopedics 2008; 31(12). pii: orthosupersite.com/ view.asp? $\mathrm{rID}=32925$

[59] Sungaran J, Harris I, Mourad M. The effect of time to theatre on infection rate for open tibia fractures. ANZ J Surg 2007; 77(10): 886-8.

[60] Skaggs DL, Friend L, Alman B, et al. The effect of surgical delay on acute infection following 554 open fractures in children. J Bone Joint Surg Am 2005; 87(1): 8-12.

[61] Ashford RU, Mehta JA, Cripps R. Delayed presentation is no barrier to satisfactory outcome in the management of open tibial fractures. Injury 2004; 35(4): 411-6.

[62] Spencer J, Smith A, Woods D. The effect of time delay on infection in open long-bone fractures: a 5-year prospective audit from a district general hospital. Ann R Coll Surg Engl 2004; 86(2): 108-12.

[63] Khatod M, Botte MJ, Hoyt DB, Meyer RS, Smith JM, Akeson WH. Outcomes in open tibia fractures: relationship between delay in treatment and infection. J Trauma 2003; 55(5): 949-54.

[64] Rohmiller MT, Kusuma S, Blanchard GM, et al. Management of open fractures of the lower extremity: do timing of operative treatment and primary wound closure really matter? OTA Abstracts, OTA 2002 - Session 3 [Retrieved: February 5, 2014].

[65] Bednar DA, Parikh J. Effect of time delay from injury to primary management on the incidence of deep infection after open fractures of the lower extremities caused by blunt trauma in adults. J Orthop Trauma 1993; 7: 523-5.

[66] Merritt K. Factors increasing the risk of infection in patients with open fractures. J Trauma 1988; 28(6): 823-7. 
[67] Chapman MW, Mahoney M. The role of early internal fixation in the management of open fractures. Clin Orthop Relat Res 1979; (138): 120-31.

[68] Russell GG, Henderson R, Arnett G. Primary or delayed closure for open tibial fractures. J Bone Joint Surg Br 1990; 72(1): 125-8.

[69] Moola FO, Jacks D, Reindl R, Berry GK, Harvey EJ. (2005, October 22). Safety of primary closure of soft tissue wounds in open fractures. OTA Abstracts, Section 11 - Paper \# 47 [Retrieved: February 5, 2014].

[70] Russell GV, Laurent S, Sasser H, \& group, O. O. F. S. (2005, October 22). Immediate versus delayed closure of grade II and IIIA tibial fractures: a prospective, randomized, multicenter study. OTA Abstracts, Session X1 - Tibia Paper \# 47 [Retrieved: February 5, 2014].

[71] Collinge C, Butterfield W, Reaves L. (2004, October 8). Soft-tissue complications with use of a protocol of aggressive debridement and primary wound closure for open injuries around the distal leg and ankle. OTA Abstracts, OTA 2004 Posters - Foot and Ankle [Retrieved: February 5, 2014].
[72] DeLong WG, Born CT, Wei SY, Petrik ME, Ponzio R, Schwab CW. Aggressive treatment of 119 open fracture wounds. J Trauma 1999; 46(6): 1049-54.

[73] Gopal S, Majumder S, Batchelor AG, Knight SL, De Boer P, Smith RM. Fix and flap: the radical orthopaedic and plastic treatment of severe open fractures of the tibia. J Bone Joint Surg Br 2000; 82(7): 959-66.

[74] Godina M. Early microsurgical reconstruction of complex trauma of the extremities. Plast Reconstr Surg 1986; 78: 285-92.

[75] Ricci WM, Collinge C, Streubel PN, McAndrew CM, Gardner MJ. A comparison of more and less aggressive bone debridement protocols for the treatment of open supracondylar femur fractures. J Orthop Trauma 2013; 27(12): 722-5.

[76] Lenarz CJ, Watson JT, Moed BR, Israel H, Mullen JD, Macdonald JB. Timing of wound closure in open fractures based on cultures obtained after debridement. J Bone Joint Surg 2010, 92(10): 19216.

(C) O'Brien et al.; Licensee Bentham Open.

This is an open access article licensed under the terms of the Creative Commons Attribution Non-Commercial License (http://creativecommons.org/licenses/by-nc/3.0/) which permits unrestricted, non-commercial use, distribution and reproduction in any medium, provided the work is properly cited. 